\title{
An integrated material metabolism model for stocks of urban road system in Beijing, China
}

\author{
Zhen Guo ${ }^{a}$, Dan $\mathrm{Hu}^{\mathrm{a}}{ }^{\mathrm{a}, *}$, Fuhua Zhang ${ }^{\mathrm{b}}$, Guolong Huang ${ }^{\mathrm{c}}$, Qiang Xiao ${ }^{\mathrm{a}}$

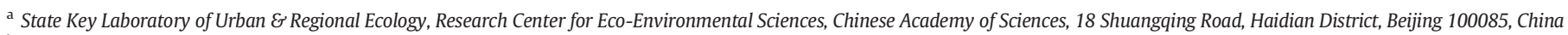 \\ b College of Resources and Environments, Southwest China University, 1 Tiansheng Road, Beibei District, Chongqing 400715, China \\ c College of Biological and Environmental Engineering, Zhejiang University of Technology, 18 Chaowang Road, Xiacheng District, Hangzhou 310014, China
}

\section{H I G H L I G H T S}

- Massive materials flow from the lithosphere into cities and form infrastructures.

- A stock model based on bottom-up method was built for calculating accumulated materials.

- Nearly $80 \%$ of the total stocks were stored in roads and $20 \%$ in ancillary facilities.

- The construction of interchanges and arteries was excessively emphasized.

- Cross-sectional parameters of low-grade roads will largely impact stocks scale.

\section{A R T I C L E I N F O}

\section{Article history:}

Received 23 May 2013

Received in revised form 7 October 2013

Accepted 13 October 2013

Available online 6 November 2013

\section{Keywords:}

Urban metabolism

Road system

Urban infrastructure

Material stock analysis

Bottom-up model

Infrastructure resource management

\begin{abstract}
A B S T R A C T
Rapid urbanization has greatly altered the urban metabolism of material and energy. As a significant part of the infrastructure, urban roads are being rapidly developed worldwide. Quantitative analysis of metabolic processes on urban road systems, especially the scale, composition and spatial distribution of their stocks, could help to assess the resource appropriation and potential environmental impacts, as well as improve urban metabolism models. In this paper, an integrated model, which covered all types of roads, intersection structures and ancillary facilities, was built for calculating the material stocks of urban road systems. Based on a bottom-up method, the total stocks were disassembled into a number of stock parts rather than obtained by input-output data, which provided an approach promoting data availability and inner structure understanding. The combination with GIS enabled the model to tackle the complex structures of road networks and avoid double counting. In the case study of Beijing, the following results are shown: 1 ) The total stocks for the entire road system reached 159 million tons, of which nearly $80 \%$ was stored in roads, and $20 \%$ in ancillary facilities. 2) Macadam was the largest stock (111 million tons), while stone mastic asphalt, polyurethane plastics, and atactic polypropylene accounted for smaller components of the overall system. 3) The stock per unit area of pedestrian overcrossing was higher than that of the other stock units in the entire system, and its steel stocks reached $0.49 \mathrm{t} / \mathrm{m}^{2}$, which was 10 times as high as that in interchanges. 4) The high stock areas were mainly distributed in ring-shaped and radial expressways, as well as in major interchanges. 5) Expressways and arterials were excessively emphasized, while minor roads were relatively ignored. However, the variation of cross-sectional thickness in branches and neighborhood roads will have a significant impact on the scale of material stocks in the entire road system.
\end{abstract}

(c) 2013 Elsevier B.V. All rights reserved.

\section{Introduction}

Urban development dominated by human activities is always accompanied by resource depletion and environmental pollution (Goudie, 2009; Rees, 1992). Cities play a central role in tackling climate change: They occupy only $2.4 \%$ of the Earth's land mass but consume $75 \%$ of the energy and emit $80 \%$ of the greenhouse gas in terms of human activity (Satterthwaite, 2008). With the urbanization process

\footnotetext{
* Corresponding author. Tel.: +86106284 9199; fax: +861062943807.

E-mail address: hudan@rcees.ac.cn (D.Hu).
}

accelerating and population growing worldwide, the study of the input, store and output of materials and energy in urban systems has gained increasing attention. By characterizing the processes of urban metabolism, researchers aim to reveal the causations of environmental and resource-related issues and develop appropriate regulatory measures accordingly (Brunner, 2007; Gandy, 2004; Kennedy et al., 2011).

As the major component of municipal infrastructure, urban roads occupy approximately more than $25 \%$ of a built-up area. Road networks constitute the pivot for urban economic development, as their wide distribution and highly developing speed are far ahead of other artificial facilities (Wee, 2012). However, the acceleration in construction 
activities has directly led to an increase in material use and energy consumption, as well as a significant accumulation within the borders of cities. Eventually, these stocks will pass their use stage, and all or part of them will be discharged as waste into the environment or be recycled and reused (Han and Xiang, 2012). For analyzing resource appropriation and recycling, as well as the environmental impacts on urban ecosystems, it is crucial to quantify the material stock (MS) (Kennedy et al., 2007; Kovanda et al., 2007).

China is undergoing a process of rapid urbanization. In 2011, the builtup area on mainland China reached $43,603 \mathrm{~km}^{2}$, with total road length and total road area jumping to $294,443 \mathrm{~km}$ and $5213 \mathrm{~km}^{2}$, respectively (MOHURD, 2011a). During this period of high-speed economic growth and continuous environmental degradation, it is of great importance to quantify the infrastructure stocks in China's megacities, especially in terms of assessing stocks in urban road systems. However, due to the limitation of data availability, quantitative studies are rare.

To fill the current gaps in the research, this paper involved the development of an integrated model for calculating the MS of urban road systems. The model incorporated all levels of roads, intersection structures (curb curve and flared intersection) and ancillary facilities into an integrated framework. On the basis of a bottom-up method, the model provided a solution for data unavailability and unknown inner structure. The combination with GIS enabled the model to cope with the complex structures of road networks and avoid double counting. Then, the model was applied in Beijing by determining local parameters, with the subsequent conducting of a series of analyses. The application of this model can provide guidance for improving existing models of urban metabolism and optimizing urban infrastructure planning and resource management.

\section{Literature review}

\subsection{A brief review of urban metabolism}

In 1965, Wolman quantitatively simulated the input and output of the overall fluxes for a hypothetical American city (Wolman, 1965). Although the infrastructure materials and other durable goods were omitted, his work is considered the pioneering work in the area of urban metabolism studies.

Over the past 40 years, significant progress has been made in the following aspects: 1) Comprehensive case studies were conducted sequentially, in such cities as Brussels, Hong Kong, Sydney, Taipei, and Toronto, which represent different geographic regions and development levels (Duvigncaud and Denayer-DeSmct, 1977; Huang et al., 2001; Newman, 1999; Sahely et al., 2003). 2) Other less-comprehensive studies focused on specific domains, such as household consumption, construction systems, urban waste, and urban industry (D'Alisa et al., 2012; D. Hu et al., 2010; Liu et al., 2005; Tarr, 2002). 3) Meanwhile, some studies targeted certain elements or materials, such as nitrogen, phosphorus, heavy metals, and PVC (Forkes, 2007; Hedbrant, 2001; M.M. Hu et al., 2010; Kleijn et al., 2000; Li et al., 2012). 4) Methods: a trend from the Odum School's Emergy Analysis, MEFA (Material \& Energy Flow Analysis) with LCA (Life Cycle Assessment) and Ecological Footprint Analysis, to Input-Occupancy-Output Analysis-based nonlinear and structured analysis combined with the state-of-the-art technologies of GIS and remote sensing.

\subsection{Review for MS and its methods on an urban scale}

Estimations of the in-use societal stock have been made for approximately 70 years, with over $70 \%$ of the publications occurring after 2000 (Gerst and Graedel, 2008). Within this rising trend, attention has gradually been paid to the accumulation of urban stocks from the perspective of urban metabolism in recent years, in which massive materials shift from the lithosphere into the anthroposphere and form buildings, infrastructure, and durables with a long life cycle (Baccini, 1996). As shown in Table 1, a number of works have examined different aspects of urban stock and there has been a gradual transition from the general MFA method to a mixed method integrated with GIS and multisource dataset, providing a large boost to the development of the study of urban metabolism.

Despite the recent boom, studies on urban stock continue to be limited by data collection (Sahely et al., 2003). Since relatively complete industry data can be found only in a few developed countries, many previous studies have adopted a top-down method, in which the Net Addition to Stocks (NAS) that enters a stock system within a specified period is calculated by determining the difference between input and output fluxes (Kovanda et al., 2007). This inevitably led to the use of macroeconomic data, such as interregional input-output tables and statistical yearbooks, among other sources. The metabolic units at various levels were usually treated as black boxes or grey boxes, which can be measured in terms of their input and output without

Table 1

Chronological review of studies in material stock on urban or regional scale since 2000.

\begin{tabular}{|c|c|c|c|c|}
\hline Authors, year & City or region of study & Analysis year & Objects of study & Model/method \\
\hline (Hedbrant, 2001) & Stockholm (Sweden) & $1900-2000$ & Heavy metal stock (Cd, Cr, Cu, Pb, Hg, Ni, Zn) & A spreadsheet model based on MFA \\
\hline (Kleijn et al., 2000) & Sweden & $1950-2100$ & PVC stock & Substance flow analysis \\
\hline (Tanikawa et al., 2002) & Kitakyushu (Japan) & $1970,1995,2020$ & Roadway and building & MFA with GIS \\
\hline (Muller, 2006) & Netherlands & $1900-2100$ & Dwelling stock & A stock dynamics model based on MFA \\
\hline (Schiller, 2007) & Germany & & Road and utility infrastructures & Material flow model \\
\hline (Kovanda et al., 2007) & Czech Republic & $2000-2002$ & Infrastructures, buildings, durables & $\begin{array}{l}\text { Economy-wide material flow accounting } \\
\text { and analysis }\end{array}$ \\
\hline (Yamaguchi et al., 2007) & Osaka (Japan) & 2007 & Urban building, infrastructure & A bottom-up model \\
\hline (Bergsdal et al., 2007) & Norway & $1900-2100$ & Dwelling stock & Dynamic material flow analysis \\
\hline (Lichtensteiger and Baccini, 2008) & Switzerland & $1900-2000$ & Buildings stock & MFA combined with ark-house method \\
\hline (Tanikawa et al., 2009) & Japan & 1975-2004 & Urban subsurface stock & Statistical methods integrated with GIS database \\
\hline (Matsuno et al., 2009) & Japan & & Copper, steel, aluminum in urban & By using DMSP/OLS nocturnal images \\
\hline (Daigo et al., 2009) & Japan & 2005 & Stainless steel stock & $\begin{array}{l}\text { Material Stock and flow analysis based on mass } \\
\text { balances of } \mathrm{Cr} \text { and } \mathrm{Ni}\end{array}$ \\
\hline (Tanikawa and Hashimoto, 2009) & $\begin{array}{l}\text { Manchester (UK) and } \\
\text { Wakayama (Japan) }\end{array}$ & $1850-2000$ & Buildings, roadways and railways & A 4d-GIS model \\
\hline (McMillan et al., 2010) & United States & $1948-2006$ & Aluminum in-use stocks & $\begin{array}{l}\text { Dynamic material flow analysis model based on } \\
\text { top-down approach }\end{array}$ \\
\hline (D. Hu et al., 2010) & Beijing (China) & 1949-2008 & Urban residential buildings & Material and energy flow analysis \\
\hline (Diamond et al., 2010) & Toronto (Canada) & 2010 & PCB stock & PCB inventory \\
\hline (Dall'O' et al., 2012) & Lombardy (Italy), & $1919-2010$ & $\begin{array}{l}\text { Residential building stock on an urban } \\
\text { scale }\end{array}$ & $\begin{array}{l}\text { A mixed method combined top-down with } \\
\text { bottom-up }\end{array}$ \\
\hline (Han and Xiang, 2012) & China & $1978-2008$ & $\begin{array}{l}\text { Residential buildings, roads, railways, } \\
\text { and water pipelines }\end{array}$ & Statistical methods \\
\hline
\end{tabular}


any knowledge or partial clarity with regard to their internal formation (Chen et al., 2010). Moreover, some data are calculated in terms of monetary value, and are generally affected by different regional markets and financial policies. These restrictions pose a great challenge with regard to conducting comparative studies and studying the stock-flow coupling relationships with higher precision. The outcomes were rarely applicable for practical policy analysis.

In a bottom-up manner, however, a stock system is disassembled into stock parts, and the total stock of a certain material is calculated by multiplying its content in each stock unit by the number of this stock unit. By this approach, both internal composition and structure of metabolic stocks can be cognized (Wang and Graedel, 2010). The outcome is a real-time accumulated stock rather than NAS.

For previous studies on urban stock, such as both overground and underground infrastructures, and durables made of metals or synthetic materials, few studies adopted the bottom-up analysis as involving multidisciplinary knowledge. With the increasing amount of infrastructure construction every year, those studies are mainly based on low-accuracy statistics, and cannot meet the demands of current civil administration and metabolism research, let alone in China, where the issues of statistical caliber disagreement across different industries and departments is frequent. In addition, the ancillary facilities of road systems did not receive due attention. With regard to integration with GIS, existing studies mainly used it to obtain road length or as a tool for presentation rather than to conduct spatial analyses for further examination of the stock alteration related to its complex networks.

\section{Methods}

\subsection{Hierarchies in urban road systems}

In urban planning within China, urban roads are classified into four types (expressways, arterial roads, secondary roads, branch roads). Each type corresponds to the specific quality of the traffic flow it bears. However, the roads inside functional zones (e.g. residential areas, factories, and schools) are outside of the arena of municipal management (SBTS, 1993). From the perspective of stocks, although these neighborhood roads (also called 'streets in blocks') are narrower and shorter than main roads, they have a larger total length. To meet increasing vehicle demands, the newly constructed or reconstructed pavement and subgrade on neighborhood roads were upgraded to the same criterion as branch roads and have been considered a part of the branch road system. In addition, to protect cultural relics, the old quarters in many Chinese cities still conserve some alleyways (known as 'hutong'), which have specific roadway and bed structures (Sorkin, 2008). As discussed above, the urban road stocks are divided into five types: expressways, arterial roads, secondary roads, branch roads (including neighborhood roads) and alleyways.

The construction of overhead and underground anilities consumes a mass of reinforced concrete to form span structures or supporting structures. Various types of materials are used for specific requirements. In recent years, a number of ancillary works have been built in Beijing to meet the need for rapid development of transportation infrastructure. From the perspective of stocks, the overhead and underground ancillary facilities (including interchanges, pedestrian overcrossings, underpass bridges and pedestrian underpasses) were also included in this model to ensure the integrity of the urban road system.

\subsection{Metabolic mode of an urban road system}

The metabolism of urban road systems is similar to that of other open systems, which involve a series of dynamic input-output flows and accumulation processes of material and energy with the surrounding and regional environment.

From the aspect of a lifecycle metabolism, there are several stages: 1) exploitation and transport of raw materials, 2) production and processing of materials or components, 3 ) construction and renovation of road systems, 4) operation and maintenance, and 5) demolition, waste treatment and reuse. Among these phases, stage 1, 2 and 5 are all related to a relatively temporary stock, while stage 4 mainly involves

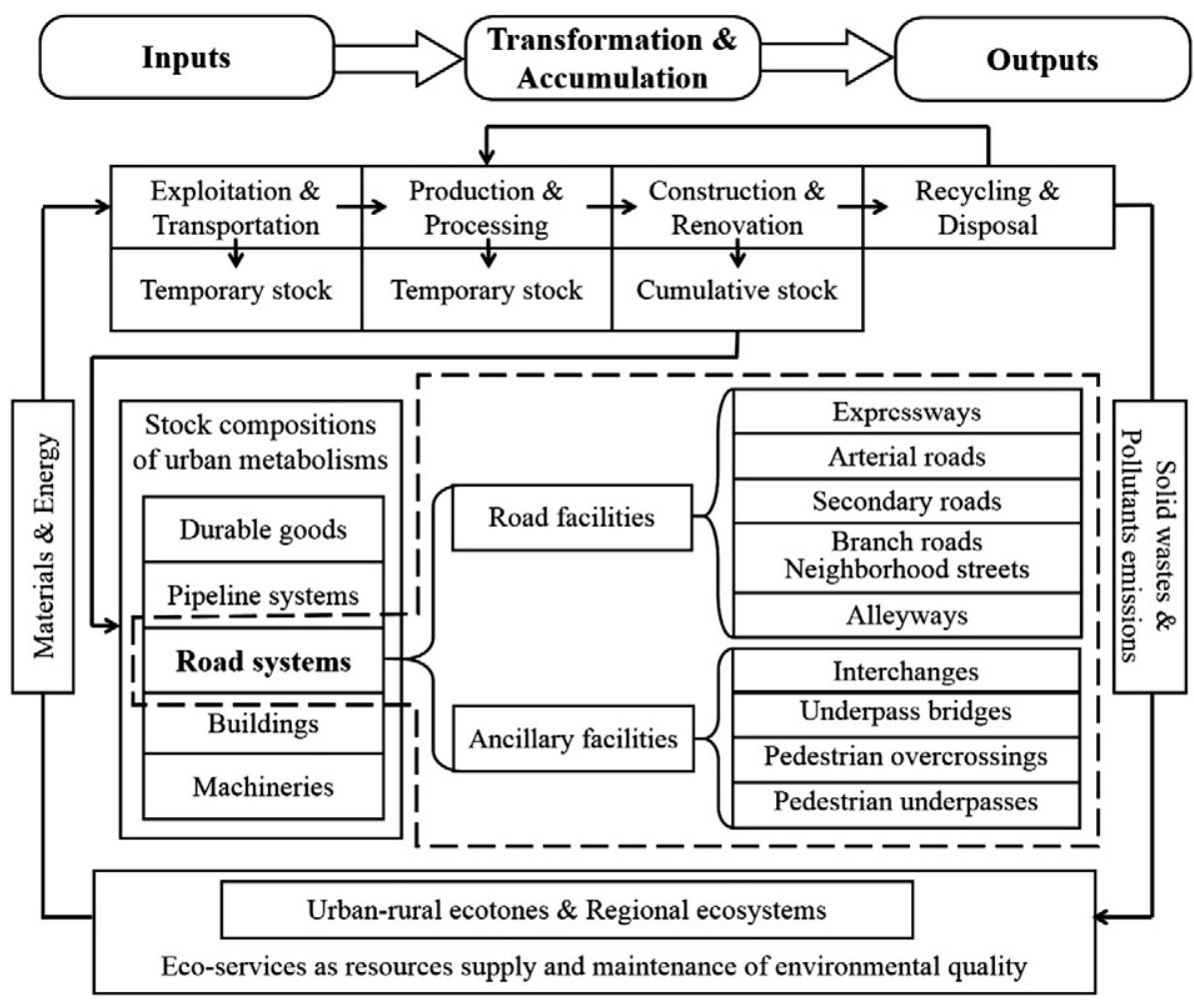

Fig. 1. A conceptual framework for urban material stocks with a lifecycle view (road system is highlighted by dash line). 
traffic emissions in use phase, with the cumulative stock occurring in stage 3. Fig. 1 demonstrates the basic metabolic mode of an urban road system.

\subsection{Stock computation model for urban road systems}

An integrated model for calculating the MS of urban road systems was constructed based on a bottom-up method, which includes a column vector that represents the accumulation of $n$ types of materials:

$\left(M_{i}\right)_{n \times 1}=\rho_{i} \times\left[\left(G S_{i}\right)_{n \times 1}-\left(A I_{i}\right)_{n \times 1}+\left(C U_{i}\right)_{n \times 1}+\left(F C_{i}\right)_{n \times 1}+\left(F I_{i}\right)_{n \times 1}+\left(G I_{i}\right)_{n \times 1}\right]$

where $M_{i}$ is the total stock of the $i$-th material in a road system and is acquired by multiplying its compaction density $\rho_{i}$ by its compaction volume in each stock unit; other parameters are presented below. For parameter elucidation following the equations, the notions for new parameters are given; others are the same as above.

$G S_{i}=\sum_{j=1}^{n_{1}} \sum_{k=1}^{n_{2}} L_{j} W_{j k} H_{i j k}$

where GS is the volume of all materials determined by accumulating the products of a roadway's sectional area at all levels with the corresponding length, without considering at-grade intersections and ancillary facilities; $n_{1}$ is the hierarchy of roads; $n_{2}$ is the type of roadway; $L_{j}$ is the total length of level-j roads; $W_{j k}$ is the width of the $k$-th roadway at the $j$-th level; and $H_{i j k}$ is the cross-sectional thickness of layer $i$ in the $k$-th roadway, the $j$-th level (See Fig. 2).

As for intersections, the nodes of multiple-intersections only account for $3 \%$ of the total node number in the study area, so we only considered the intersection between two roads; the differences between cross-type and staggered intersections, and between T-shaped and Y-shaped intersections were omitted. The equation of double counting at at-grade intersections is as follow:

$$
\begin{aligned}
A I_{i}= & \sum_{j_{1}=1}^{n_{1}} \sum_{j_{2} \geq j_{1}}^{n_{1}}\left[\frac{1}{2} W_{j_{1} k_{c}} W_{j_{2} k_{c}} H_{i j_{2} k_{c}}\right. \\
& \left.+\left(2 W_{j_{1} k_{f}} W_{j_{2} k_{f}}+W_{j_{1} k_{f}} W_{j_{2} k_{c}}+W_{j_{1} k_{c}} W_{j_{2} k_{f}}\right) H_{i j_{2} k_{f}}\right] P_{j_{1} j_{2}}
\end{aligned}
$$

where $A I$ means the volume repeatedly calculated (see Fig. 3(a),(b)); $j_{1}$ and $j_{2}$ are two intersected roads at different levels, while a larger subscript means a higher level (usually the cross-sectional structure at an at-grade intersection is designed per the standard of a relatively higher level.); $k_{f}$ represents a footway; $k_{c}$ represents the total carriageway; and
$P_{j 1 j 2}$ is the converted number of nodes on the two intersected roads, which is calculated in Eq. (8).

In Eq. (4), the total volume of curbs equals the total crosssectional area of curbs at all levels, multiplied by the total road length correspondingly, then subtracted by the volume of double counting at intersections:

$$
C U_{i}=\sum_{j_{1}=1}^{n_{1}}\left(R_{i} N R_{j_{1}}+F_{i} N F_{j_{1}}\right)\left(L_{j_{1}}-\frac{1}{2} \sum_{j_{2}=1}^{n_{1}} P_{j_{1} j_{2}} \sum_{k=1}^{n_{2}} W_{j_{2} k}\right)
$$

where $C U$ is the volume of materials contained in curbs; $R$ and $F$ are the cross-sectional areas of single raised curbs and flush curbs, respectively; and NR and NF are the cross sectional numbers of raised curbs and flush curbs at different road levels, respectively.

Eq. (5) refers to the MS of curb curves; the curb curves at different levels of intersections are calculated by using the ellipse fillet curves model:

$F C_{i}=\sum_{j_{1}=1}^{n_{1}} \sum_{j_{2} \geq j_{1}}^{n_{1}}\left(2-\frac{\pi}{2}\right) E_{j_{1}} E_{j_{2}} P_{j_{1} j_{2}} H_{i j_{2} k_{c}}$

where $F C$ is the volume of materials contained in curb curves (see Fig. 3(c)) and $E_{j}$ is the curb radius at the $j$-th level.

The calculation of MS in flared intersections is given in Eq. (6):

$F I_{i}=\sum_{j_{1}=1}^{n_{1}} \sum_{j_{2} \geq j_{1}}^{n_{1}}\left[T_{j_{1}}+T_{j_{2}}-I_{j_{1}} O_{j_{2}}-O_{j_{1}} I_{j_{2}}\right] P_{j_{1} j_{2}} H_{i j_{2} k_{c}}$

where $F I$ is the volume of materials contained in flared intersections (see Fig. 3(d)); $I_{j}$ and $O_{j}$ are the broadened boundary lines of access and exit roads at the $j$-th level, respectively; and $T_{j}$ is the sum of broadened areas of access and exit roads at the $j$-th level, which is calculated in Eq. (9).

The MS of ancillary facilities such as interchanges and pedestrian overcrossings can be determined through Eq. (7):

$G I_{i}=\sum_{x} \sum_{y} C_{x y} A_{i x y}$

where $G I$ is the volume of materials contained in the ancillary facilities; $x$ is the type of ancillary facility; $y$ is the level based on structural complexity; $C$ is the number of ancillary facilities; and $A_{i}$ is the average compaction volume of material $i$ in a certain ancillary facility unit.

$P_{j_{1} j_{2}}=\operatorname{Node}_{3}\left(j_{1}, j_{2}\right)+2 \operatorname{Node}_{4}\left(j_{1}, j_{2}\right)$

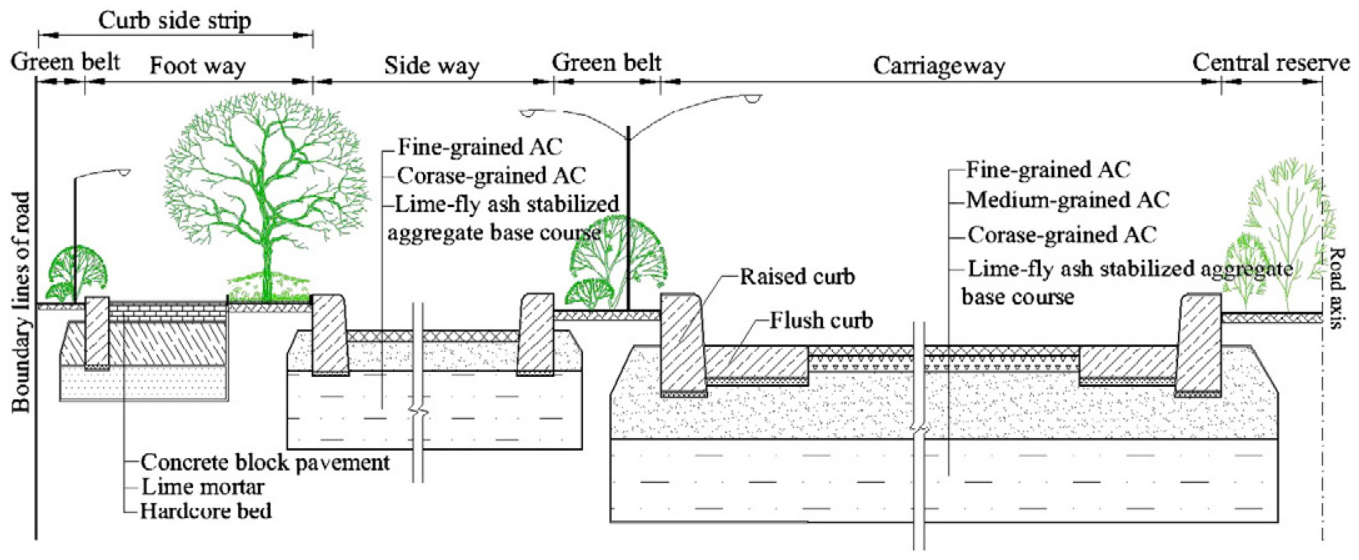

Fig. 2. Cross-sectional structure of a typical urban road. 


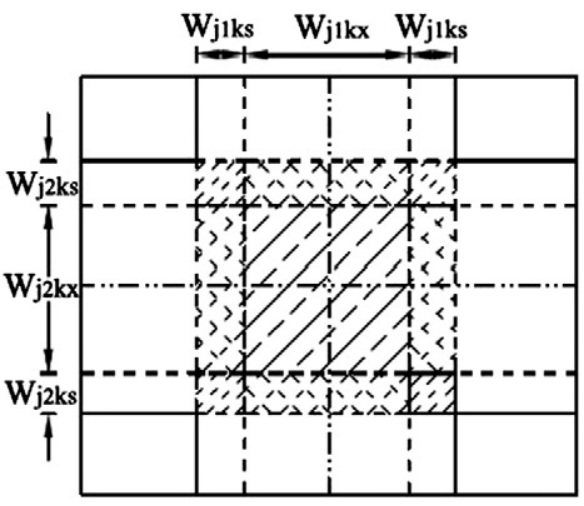

(a)

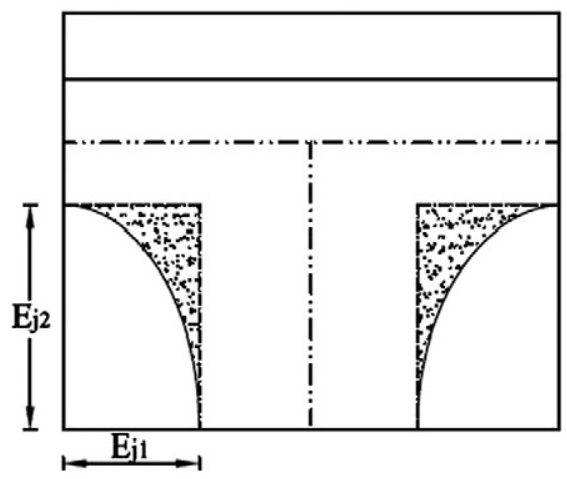

(c)

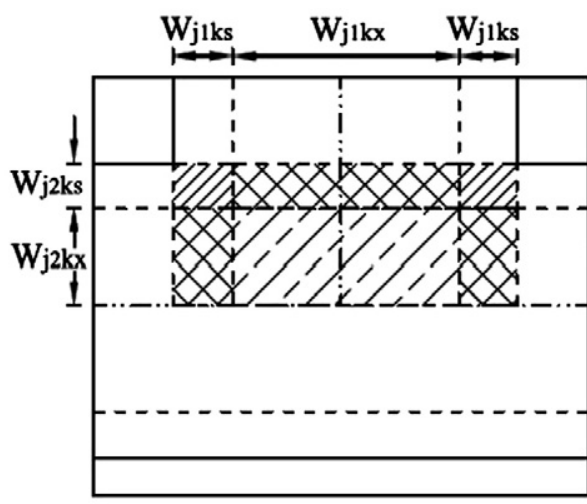

(b)

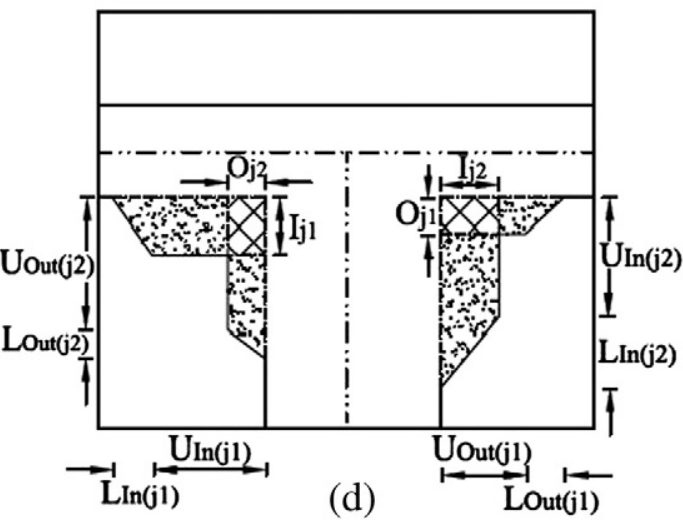

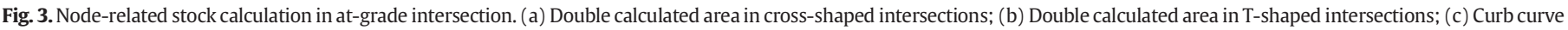
design for T-shaped intersections; (d) Flared design for T-shaped intersections.

where $\mathrm{Node}_{3}$ and $\mathrm{Node}_{4}$ are the numbers of T-shaped and cross-shaped nodes at two intersected roads, respectively.

$T_{j}=\frac{1}{2}\left[\left(2 U_{\text {In }}(j)+L_{\text {In }}(j)\right) I_{j}+\left(2 U_{\text {Out }}(j)+L_{\text {Out }}(j)\right) O_{j}\right]$

where $U_{I n}$ and $L_{I n}, U_{\text {Out }}$ and $L_{\text {out }}$ are the broadened width and the broadened transition zone length for a certain access road and exit road, respectively.

\section{Data}

\subsection{An overview of the study area}

As the capital and a municipality of China, Beijing is a transport hub with a sophisticated network of roads. Six completed ring-shaped roads serving as the fundamental frameworks encircle the built-up areas. Inner and outer ring roads are connected by nine expressways heading in virtually all compass directions, supplemented by eleven China National Highways. Other roads are laid out mainly along north-south and east-west grids and form a chessboard-typed structure. In this study, the urban road systems within the 5th ring were considered (Fig. 4), covering an area of $667.2 \mathrm{~km}^{2}$.

\subsection{Parameter acquisition}

The parameter acquisition for this model is related to the road information for various dimensions, including points, lines and polygons. Correspondingly, the database was built by integrating multi-source data.

\subsubsection{Nodes and linear parameters}

The land cover in urban areas shows a highly spatial heterogeneity. For lower-level roads, low-resolution images almost become a bottleneck in terms of retrieving valid information. In this paper, the length information was extracted from QuickBird images $(0.6 \mathrm{~m}$ resolution in panchromatic band) and by digitalizing published thematic maps as a supplement. By collecting the data of roadway types, road width and pavement texture, we established a characteristic library for different classes of roads within the study area. Through a comprehensive utilization of the spectrum, texture and shape (length-width ratio) of surface objects and optimizing the rule set by repeating identification, an extraction based on object-oriented method was carried out with the Envi $4.8 \mathrm{EX}$ platform. Due to the shading influence from buildings and roadside trees, unextractable information, especially with regard to minor roads, was complemented by field measurements, which involved positions data obtained by GPS devices (Trimble JUNO SB) and length data obtained by a laser distance meter (Leica D5). Node information including the distribution, type and quantity of 3-nodes and 4-nodes were obtained by calculating the geometric intersection of all the vectorial layers of roads. The incorrect pseudo-nodes and redundant data from different sources were removed by topological analysis, in which rules were defined to restrain the way in which features may share a geographic space and maintain data integrity through managing topological primitives. The results are shown in Table 2 for length information and Table 3 for node statistics.

\subsubsection{Structure of roadway and bed courses}

A spatial sampling of 250 roads including all types of roads within the 5th ring was selected randomly through ArcGIS. By using GPS, we determined the roads' positions. A laser survey was carried out to collect pavement parameters, including the types and widths of roadways. Finally, we collected 238 valid datasets including different sections of road. The indices include the width of vehicle lanes, the width of nonmotor vehicle lanes, the width of shared lanes, the width of central and bilateral green belts and the width of footways (Fig. 2). The structure 


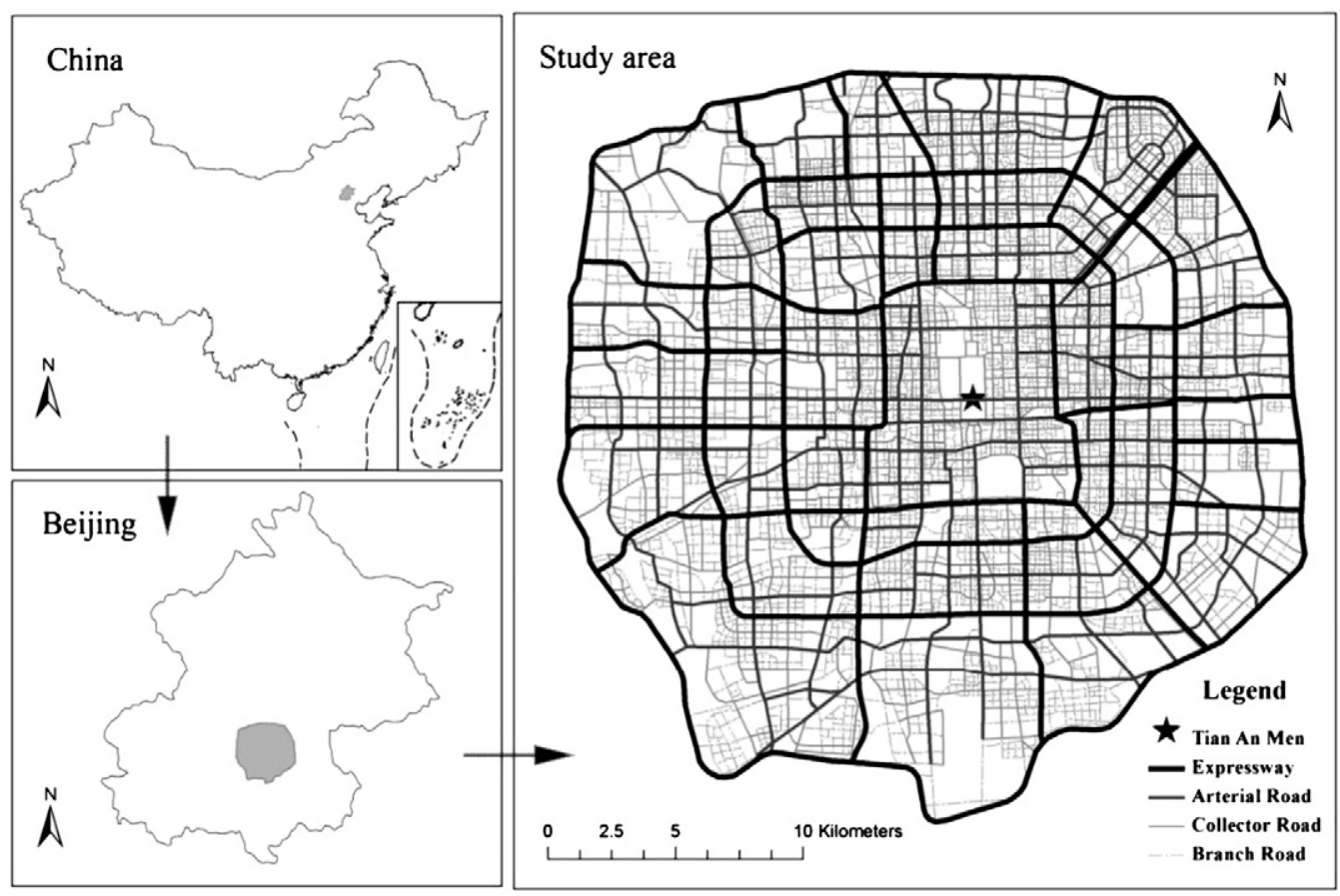

Fig. 4. The urban road system for the studied area in Beijing.

and width of typical roadways at all levels were obtained by statistically analyzing the measured data (Table. 4).

The structures of pavement and subgrade are not only related to the properties of traffic flow, but also to the soil, geological conditions, latitude and climate (Russam and Coleman, 1961). These parameters were determined by referring to various data sources, including the standards for urban road design and construction in Beijing, 12 typical cases covering all levels of roads, expert consultation with the Beijing Municipal Committee of Communications (BMCC) and field investigation (during pipeline and subway construction). The parameters are listed in Table 5.

In the study area, the bed courses of footways are usually of a triplelayer structure, namely a 0.06 -m layer of precast concrete blocks, a 0.03 $\mathrm{m}$ layer of lime-mortar (1:3) and a $0.1-\mathrm{m}$ bed of macadam and lime. The flush curbs and raised curbs were treated as $0.8 \mathrm{~m} \times 0.3 \mathrm{~m} \times 0.1 \mathrm{~m}$ and $0.5 \mathrm{~m} \times 0.1 \mathrm{~m} \times 0.25 \mathrm{~m}$ (general size), respectively.

\subsubsection{Curb curve and flared intersection}

In the civil engineering of municipal roads, curb curves and broadening at intersections are designed according to vehicle speed and traffic flow, so as to improve traffic efficiency and driving safety (MCC, 1995; MOHURD, 2011b). The relevant parameters in curb curves and flared intersections were provided by the National Urban Road Design Standards (Tables 6 and 7) (SBTS, 1993; MCC, 1995). The roads with lower traffic flow and used mainly for light motor vehicles, such as neighborhood roads and hutongs, do not adopt the same construction regulations as municipal roads. The stocks generated from the same parts of interchanges were contained within the module of ancillary facilities.

\subsubsection{Stock computation for ancillary facilities}

Like other megacities, Beijing has a complicated interchange system. Flyovers come in all shapes and sizes. Individual differences make it

Table 2

The length of different categories of urban road in the study area.

\begin{tabular}{|c|c|c|c|c|c|c|c|}
\hline & Expressways & Arterial roads & Secondary roads & Branch roads ${ }^{\mathrm{a}}$ & Hutongs & Total road length & Road density \\
\hline Length & $384.8 \mathrm{~km}$ & $562.3 \mathrm{~km}$ & 776.9 km & $5184.3 \mathrm{~km}$ & $212.4 \mathrm{~km}$ & $7120.6 \mathrm{~km}$ & $10.7 \mathrm{~km} / \mathrm{km}^{2}$ \\
\hline
\end{tabular}

${ }^{\text {a }}$ Here branch roads include neighborhood roads.

Table 3

Node composition in different categories of intersections.

\begin{tabular}{|c|c|c|c|c|c|c|c|c|c|c|c|}
\hline & \multicolumn{2}{|c|}{ Expressways } & \multicolumn{2}{|l|}{ Arterial roads } & \multicolumn{2}{|c|}{ Secondary roads } & \multicolumn{2}{|l|}{ Branch roads } & \multicolumn{2}{|l|}{ Hutongs } & \multirow[t]{2}{*}{ Total } \\
\hline & 3 nodes & 4 nodes & 3 nodes & 4 nodes & 3 nodes & 4 nodes & 3 nodes & 4 nodes & 3 nodes & 4 nodes & \\
\hline Expressways & 34 & 24 & & & & & & & & & 58 \\
\hline Arterial roads & 51 & 124 & 49 & 100 & & & & & & & 324 \\
\hline Secondary roads & 134 & 111 & 170 & 301 & 159 & 185 & & & & & 1060 \\
\hline Branch roads $\left({ }^{\mathrm{a}}\right)$ & $414(414)$ & $79(508)$ & $820(821)$ & $304(1482)$ & 932(932) & $737(2662)$ & $1405(12908)$ & $793(7472)$ & & & $5484(27,199)$ \\
\hline Hutongs & 0 & 1 & 0 & 66 & 3 & 241 & 327 & 646 & 411 & 22 & 1717 \\
\hline $\operatorname{Total}\left({ }^{\mathrm{a}}\right)$ & 633(633) & $339(768)$ & 1039(1040) & 771(1949) & 1094(1094) & 1163(3088) & 1732(13235) & 1439(8118) & 411 & 22 & $8643(30,358)$ \\
\hline
\end{tabular}

a Bracketed number indicates nodes include streets in blocks. 
Table 4

Statistical types and width of roadways for different categories of urban road in the study area.

\begin{tabular}{|c|c|c|c|c|c|c|c|c|}
\hline Category & \multicolumn{5}{|c|}{ Structure and width of road way (m) } & Total width (m) & No. of typical roads/sample size/(\%) & P value* \\
\hline Hutongs & $4.73 \pm 0.99^{c}$ & & & & & $4.73 \pm 0.99$ & $29 / 32(90.6 \%)$ & 0.903 \\
\hline Branch roads & $2.79 \pm 1.18^{\mathrm{f}}$ & $7.11 \pm 1.94^{\mathrm{c}}$ & & & & $12.54 \pm 3.13$ & $37 / 44(84.1 \%)$ & 0.247 \\
\hline Secondary roads & $4.01 \pm 1.2^{\mathrm{f}}$ & $15.6 \pm 4.53^{c}$ & & & & $23.61 \pm 4.39$ & $68 / 75(90.7 \%)$ & 0.439 \\
\hline Arterial roads & $3.97 \pm 1.00^{\mathrm{f}}$ & $5.75 \pm 1.54^{\mathrm{s}}$ & $2.60 \pm 1.27^{\mathrm{g}}$ & $13.04 \pm 3.02^{c}$ & $3.46 \pm 1.38^{\mathrm{g}}$ & $48.13 \pm 6.71$ & $46 / 53(86.8 \%)$ & 0.261 \\
\hline Expressways & $4.53 \pm 1.05^{\mathrm{f}}$ & $11.62 \pm 2.56^{\mathrm{s}}$ & $2.91 \pm 1.12^{\mathrm{g}}$ & $16.36 \pm 2.78^{c}$ & $3.09 \pm 1.31^{\mathrm{g}}$ & $67.57 \pm 9.43$ & $31 / 34(91.2 \%)$ & 0.813 \\
\hline
\end{tabular}

' $c$ ' Indicates carriage way or main way of road, ' $\mathrm{f}$ indicates foot way, 's' indicates side way, ' $\mathrm{g}$ ' indicates green belt or central reserve.

* Shapiro-Wilk method was adopted in test of normality. The P value $>0.05$ means it obeys normal distribution.

Table 5

The parameters of bed structure layers for different categories of urban road in the study area (m).

\begin{tabular}{|c|c|c|c|c|c|c|}
\hline & Expressways & Arterial roads & $\begin{array}{l}\text { Side-ways of } \\
\text { expressways }\end{array}$ & $\begin{array}{l}\text { Secondary roads/side-ways } \\
\text { of arterial roads }\end{array}$ & $\begin{array}{l}\text { Branch roads/streets } \\
\text { in blocks }\end{array}$ & $\begin{array}{l}\text { Non-motor vehicle } \\
\text { lanes/hutongs }\end{array}$ \\
\hline SMA & 0.04 & - & - & - & - & - \\
\hline Fine-grained AC & - & 0.04 & 0.04 & 0.04 & 0.04 & 0.04 \\
\hline Medium-grained AC & 0.06 & 0.05 & - & - & 0.05 & - \\
\hline Coarse-grained $\mathrm{AC}$ & 0.08 & 0.07 & 0.07 & 0.07 & - & - \\
\hline Lime-flyash stabilized aggregate & 0.51 & 0.5 & 0.48 & 0.45 & 0.36 & 0.36 \\
\hline Total depth & 0.69 & 0.66 & 0.59 & 0.56 & 0.45 & 0.4 \\
\hline
\end{tabular}

SMA (stone mastic asphalt), AC (asphalt concrete).

Table 6

Turn radius of curb side strips for different categories of urban roads.

\begin{tabular}{lllll}
\hline & Expressways & $\begin{array}{l}\text { Arterial } \\
\text { roads }\end{array}$ & $\begin{array}{l}\text { Secondary } \\
\text { roads }\end{array}$ & $\begin{array}{l}\text { Branch } \\
\text { roads }\end{array}$ \\
\hline Mean speed of right turn $(\mathrm{km} / \mathrm{h})$ & 30 & 25 & 20 & 15 \\
Turn radius of curb side strips $(\mathrm{m})$ & 35 & 25 & 15 & 10 \\
\hline
\end{tabular}

practically infeasible to calculate the total MS. In this paper, a land use scale coefficient was introduced, and together with high-resolution images was used to calculate the coverage area for each type of interchange (Table 8). By means of sample statistics, we can determine typical parameters and collect relevant projects that meet the required conditions. Based on the bridge structure, stocks were disassembled into three parts (supporting structure, main line, and ramp), and then the material mass in substructure and superstructure were calculated respectively (Table 9 ). With this method, we can effectively compute the total MS for interchanges by using limited engineering cases, in an attempt to study the stock system of complex artificial structures.

Field surveys show that most pedestrian overcrossings were in a steel box girder structure. After conducting a statistical analysis for

Table 7

The parameters for flared intersections $(\mathrm{m})$.

\begin{tabular}{|c|c|c|c|c|c|c|}
\hline \multirow{2}{*}{$\begin{array}{l}\text { Type of } \\
\text { intersection }\end{array}$} & \multicolumn{2}{|c|}{ Arterial roads } & \multicolumn{2}{|c|}{ Secondary roads } & \multicolumn{2}{|c|}{ Branch roads } \\
\hline & Access road & Exit road & Access road & Exit road & Access road & Exit road \\
\hline Art. to art. & $15 / 120 / 50^{\mathrm{a}}$ & $10 / 80 / 30$ & - & - & - & - \\
\hline Art. to sec. & $10 / 100 / 40$ & $5 / 70 / 20$ & $10 / 70 / 40$ & $5 / 50 / 20$ & - & - \\
\hline Art. to bra. & $5 / 70 / 30$ & $3 / 50 / 15$ & - & - & $5 / 40 / 30$ & $3 / 30 / 15$ \\
\hline Sec. to sec. & - & - & $10 / 70 / 30$ & $5 / 50 / 15$ & - & - \\
\hline Sec. to bra. & - & - & $5 / 60 / 30$ & $3 / 40 / 15$ & $5 / 40 / 30$ & $3 / 30 / 15$ \\
\hline Bra. to bra. & - & - & - & - & $5 / 40 / 30$ & $3 / 20 / 15$ \\
\hline
\end{tabular}

${ }^{a}$ Broadening value of boundary lines/lengths of flared zones/lengths of transition zones.

Table 8

Statistical analyses of floor area relations for the different types of interchanges.

\begin{tabular}{llrl}
\hline & $\begin{array}{l}\text { No. of samples/total } \\
\text { in study area }\end{array}$ & Floor area & $\begin{array}{l}\text { Floor area } \\
\text { ratio }\end{array}$ \\
\hline Hub interchanges & $22 / 59$ & $12.68 \pm 3.72$ ha & 7 \\
General interchanges & $49 / 130$ & $5.35 \pm 1.46$ ha & 3 \\
Separate interchanges & $73 / 194$ & $1.79 \pm 0.80$ ha & 1 \\
\hline
\end{tabular}

360 samples, we obtained the general scale of pedestrian overcrossings (Table 10). By means of typical case, the stocks were deconstructed into three parts: ramp (including stairs-ramp for pedestrians and ramp for bicycles and motorcycles), passageway (including the major structure of steel box girder and bridge railings) and supporting structure. Then, the stock in both substructure and superstructure were calculated as interchanges (Table 11).

\section{Results}

\subsection{Compositional analysis}

In the upper part of Fig. 5, the results of the stock composition of urban road systems in the study area are shown. The total stocks in the overall road systems reached 159 million tons, of which $79.9 \%$ was stored in road facilities and $20.1 \%$ in ancillary facilities. Among road facilities, neighborhood streets, expressways and arterial roads were the top three stock units, accounting for more than $70 \%$ of the sum

Table 9

Raw material inputs for typical separate interchanges ( $t$ ).

\begin{tabular}{lllcclll}
\hline & Cement & Grit & Macadam & Steel & Asphalt & SMA & APP \\
\hline Substructure & 1224.5 & 1512.7 & 3313 & 423 & - & - & - \\
Superstructure & 5118.2 & 5971.3 & $12,781.4$ & 464 & 661.7 & 32.6 & 6.2 \\
Total & 6342.6 & 7484 & $16,094.3$ & 887 & 661.7 & 32.6 & 6.2 \\
\hline
\end{tabular}

Table 10

Statistical analyses of floor area relations for pedestrian overcrossings.

\begin{tabular}{lllll}
\hline & No. of sample & Min. & Max. & Floor area \\
\hline $\begin{array}{c}\text { Pedestrian } \\
\text { overcrossings }\end{array}$ & 360 & $156.5 \mathrm{~m}^{2}$ & $1821.0 \mathrm{~m}^{2}$ & $517.3 \pm 271.1 \mathrm{~m}^{2}$ \\
\hline
\end{tabular}

Table 11

Raw material inputs for typical pedestrian overcrossings ( $t$ ).

\begin{tabular}{lrrrrl}
\hline & Cement & Grit & Macadam & Steel & $\begin{array}{l}\text { Polyurethane } \\
\text { plastics }\end{array}$ \\
\hline Substructure & 187.1 & 241.4 & 523.8 & 35.9 & - \\
Superstructure & 2.5 & 2.7 & 6.3 & 214.9 & 10.1 \\
Total & 189.7 & 244.1 & 530.1 & 250.8 & 10.1 \\
\hline
\end{tabular}




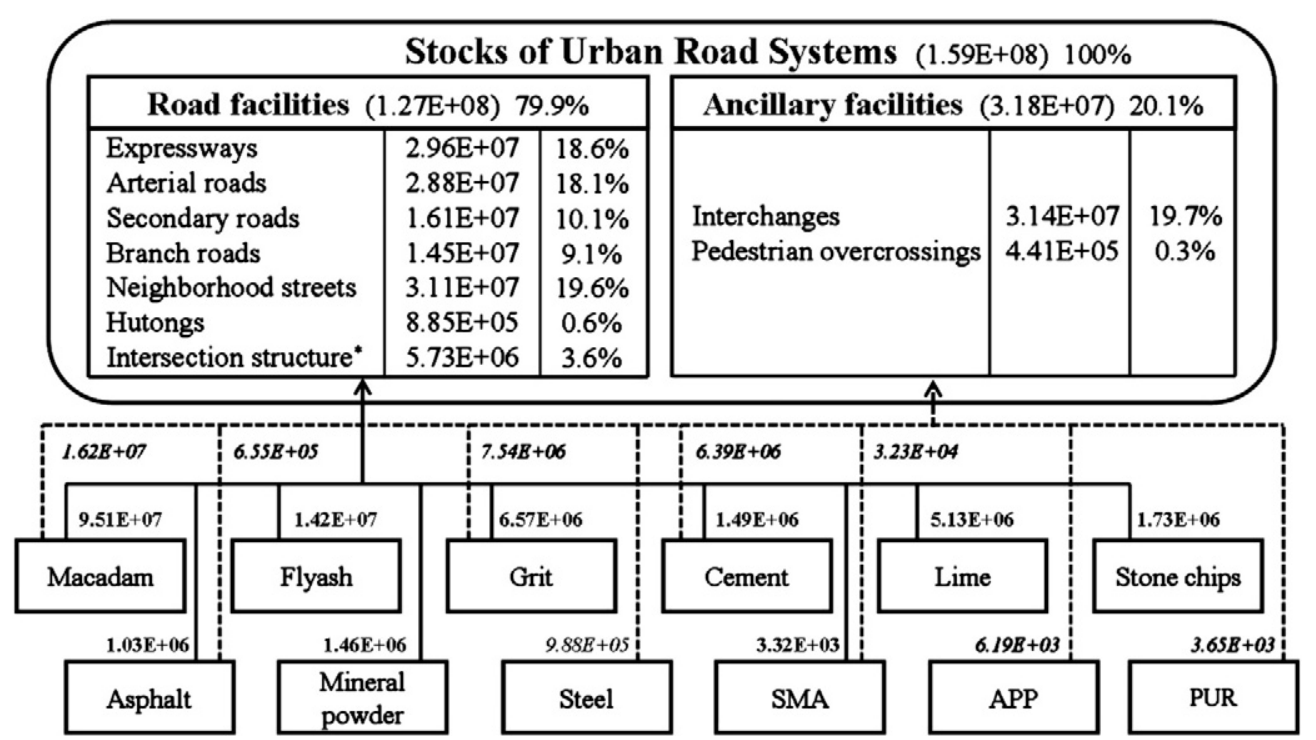

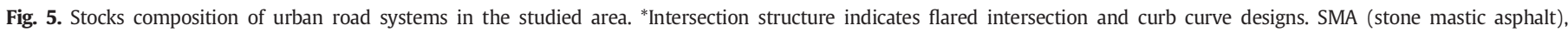
PUR (polyurethane plastics), APP (atactic polypropylene).

stock in road facilities. Secondary roads and branch roads came second, with each accounting for approximately $12 \%$ in road facilities. The stock contributed by intersection structure amounted to 5.73 million tons, which was 5 times greater than that of hutongs. As for ancillary facilities, the two stock units were distinctly different, as interchanges had the maximum stock (31.4 million tons) in the entire system, while pedestrian overcrossings had the minimum MS (441 kt).

The compositions of raw materials are presented in the lower section of Fig. 5. Among all the materials, macadam, flyash and grit, which are widely used in road bed and aggregate grading, constituted the top three largest stocks and accounted for approximately $88 \%$ of the total stock system. SMA (stone mastic asphalt), PUR (polyurethane plastics) and APP (atactic polypropylene) accounted for smaller parts of the entire stock system. As modified asphalt, SMA has high durability, skid resistance and low noise. Due to high cost, it is mainly used in highlevel roads and viaducts, only accounting for $0.02 \%$ of the total stock. PUR and APP are used exclusively in ancillary facilities, as PUR is used for surface paving in pedestrian overcrossings and APP is mainly used for interchange anti-seepage, each with a proportion less than $1 \%$ of the total stock.
The ratios of other materials were in the mid-range. Among them, lime, stone chips and mineral powder, which are used as admixture in the surface course or subgrade of roads for enhancing cohesiveness and strength, accounted for 3.2\%, $1.1 \%$ and $0.9 \%$ of the total stocks, respectively. Steels, used exclusively in ancillaries in the form of isolation guardrails, span-parts of interchanges and steel-box-girder structures, amounted to $988 \mathrm{kt}$. Cement and asphalt are widely used both in roads and ancillaries. The former is mainly used for preparing graded concretes, while the latter is used for impervious paving; they accounted for $5.0 \%$ and $1.1 \%$ of the total stock, respectively.

\subsection{Comparative analysis per unit area}

Stock per unit area is mainly related to the vertical structure. The construction of span structures required a mass of reinforced concrete. Consequently, the two units with the largest stock per unit area were pedestrian overcrossings and interchanges (see Fig. 6). In terms of road facilities, expressways had the highest stock per unit area, while arterial roads came second, followed by hutongs and secondary roads, with branch roads being the lowest. With the implementation of old

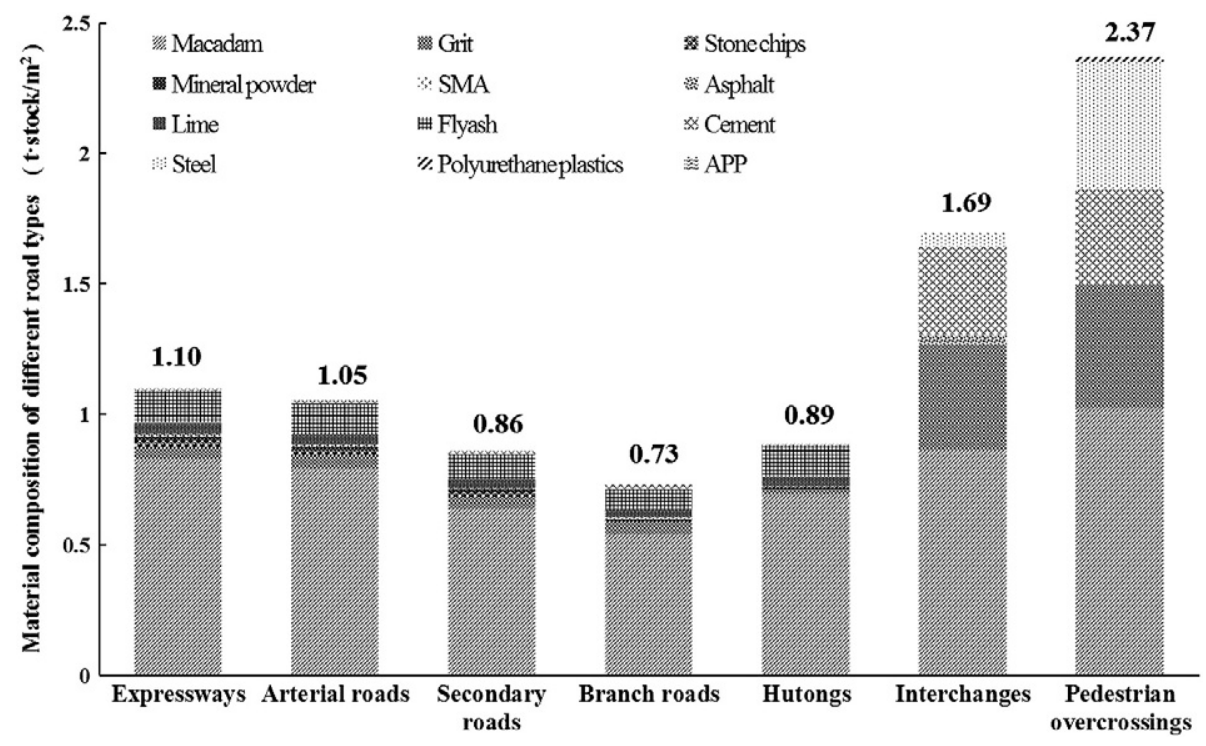

Fig. 6. Material composition of different types of stock units (per unit area). 


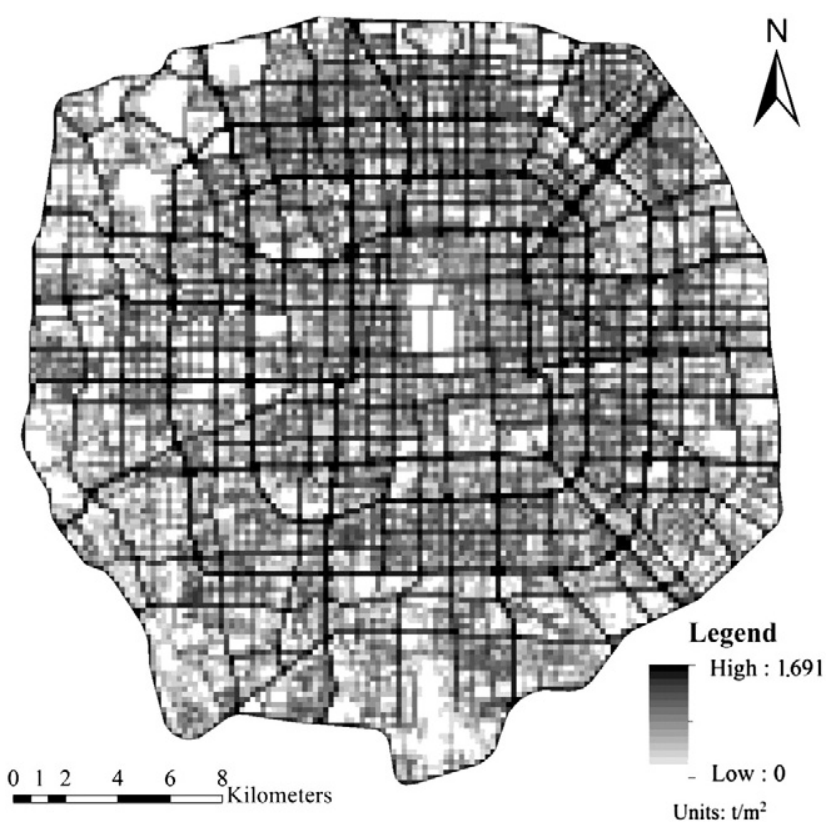

Fig. 7. Spatial distribution of stocks for urban road system within Beijing the 5th Ring Road.

city reconstruction, hutongs show a different rank from that of traffic bearing capacity.

With regard to material composition, macadam, steel, sand and concrete account for $98.5 \%$ of total stock per unit area in ancillary facilities. In road facilities, the major components were macadam and flyash, other materials account for less than $5 \%$. Sand and cement had stocks of $0.44 \mathrm{t} / \mathrm{m}^{2}$ and $0.35 \mathrm{t} / \mathrm{m}^{2}$, respectively, in ancillary facilities, 9.4 and 35.2 times higher than that in road facilities, respectively. Steel stocks per unit area in pedestrian overcrossings reached $0.49 \mathrm{t} / \mathrm{m}^{2}, 10$ times as high as those in interchanges, while steel was not utilized in roads.

\subsection{Spatial distribution}

The spatial distribution of road stocks was presented in Fig. 7. The results indicated that the areas with high stock value were mainly distributed in the ring-shaped and radial expressways, as well as in the large interchanges formed by major expressways and arterial roads. The city's parks and water bodies, with different scales, formed varying sizes of low value areas, and were dispersedly inset in road stock landscapes.

By using Fragstats, we further conducted a local gradient analysis for determining the spatial variation of the road stocks and other roadrelated landscape indicators in different directions (Fig. 8). The moving windows analysis of the stocks, the length, the area of road per unit area, the number of nodes and the number of block patches per unit area all showed that there was an obviously low-stock area existing in the central area within the 2 nd ring road. The government banned the extensive road expansion projects within the old city in order to protect the historical style of the Imperial Palace, resulting in a relative decline in road stock. The upward trend of road stock was clear between the 2nd and the 4th ring roads, despite a fluctuation generated by other non-construction land use. Near the urban fringe, a declining trend was presented with the decrease in population density and building density.

\section{Discussion}

\subsection{Sensitivity analysis}

Based on the bottom-up way, the contribution of all model variables can be measured through sensitivity analysis. The variables were classified into several groups according to the different stock units, and the regression slopes were used to rank both groups and individual parameters.

Among the five groups in length dimension (Fig. 9(a)), the thickness of cushion layers has the highest contribution to the total stock, followed by the width of carriageways and the broadening on flared intersections; the lowest is total length. That is to say, considering that branch and neighborhood roads account for more than $70 \%$ of the total road length in the studied area, the variation of their crosssectional parameters has a large impact on the scale of the total MS, while the total length of hutongs has the smallest contribution.

With respect to those parameters in quantity units (Fig. 9(b)), we assume that their changes have no relationship with road length. In ancillary facilities, the quantity of all types of interchanges has a larger contribution than that of pedestrian overcrossings. The node quantity of branch roads (slope $=-73.2$ ) and hutongs (slope $=-9.5$ ) are the only two parameters that are in negative correlation to the total MS. Given that high-level nodes usually refer to interchanges, more branch and hutong nodes mean more overlapping spaces, indicating that the microcirculation structure in road systems may be important for regulating the total stock.

Compared with other recommended ratios of the pyramid-shaped structure (MCC, 1995; ITE, 1997), the grading ratio of the four levels of municipal roads (1:1.5:2:4.3) presented an unreasonable structure. The construction of expressways and arterial roads was excessively emphasized over the past several decades while secondary roads and branch roads were ignored, which not only led to an increase in road area in the same total length per unit area, but also resulted in high traffic pressure on the main road networks and obstruction in minor roads. From another perspective, excessive road width causes inconvenience in terms of crossing and will certainly result in unnecessary material consumption and land resource waste. Therefore, one potential means by which to relieve urban traffic loading and reduce traffic jams is to properly adjust the hierarchical proportions of road stocks.

\subsection{The ancillary facilities of the road system in Beijing}

Almost all of the studies of infrastructure neglect to take interchanges into consideration. However, there are 401 interchanges (including 34 hub interchanges) in downtown Beijing, with a total length of $15.3 \mathrm{~km}$ (BMCT, 2011). Being the largest stock unit, interchanges account for $19.7 \%$ of the total MS. This is unique not only in China but also in the world as a whole. In addition to paying more attention to the mass resource appropriation, we should realize that such large-scale construction of grade separation is not going to solve the progressively worsening traffic congestion (Yin et al., 2012). Rather, the increasing number of interchanges will inevitably lead to an increase in ramps, which are slanted, coiling and may potentially affect traffic pollutant emissions. In recent decades, the air quality in Beijing has deteriorated due to vehicles' emissions (Guo et al., 2012). Dust haze-prone weather implies that urban transportation systems must enter a transformative stage, not only in Beijing but also in many Chinese cities. Besides governing automobile exhaust, urban managing and planning departments should be paying closer attention to the details of road and transport system construction.

The quantity of pedestrian overcrossings increased by $56.2 \%$ from 2005 to 2011. Meanwhile pedestrian underpasses also increased by $13.4 \%$, although they were not considered in the modeling (BMCT, 2011). However, the results so far indicate that ancillaries for pedestrians account for only a tiny part of the entire system. Moreover, with the upward hierarchy of roads, the proportion of footways in the total road width decreases from $44.5 \%$ in branch roads to $13.4 \%$ in expressways. People living downtown feel an obvious deterioration in the ease of commuting by foot or by bicycle; gone are the days when the priority was the pedestrian and the private car explosion had not yet occurred. It is rational to suggest that Beijing should implement on 


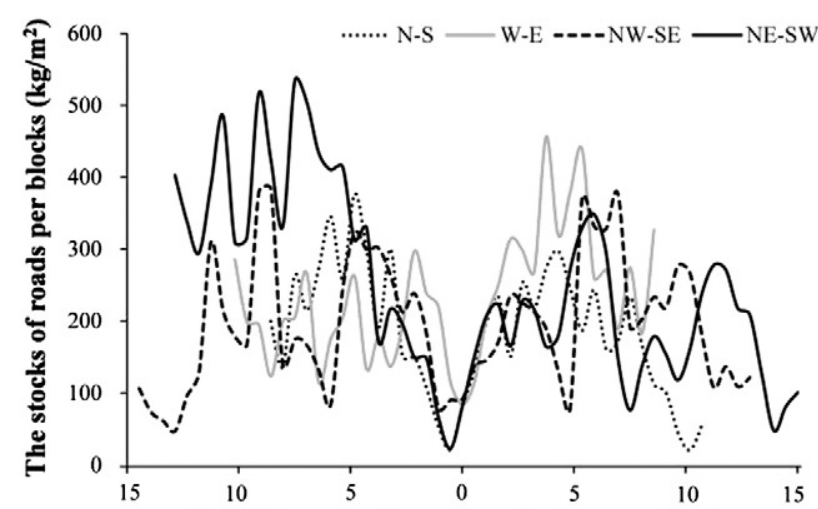

(a) Distance form the city center $(\mathrm{km})$

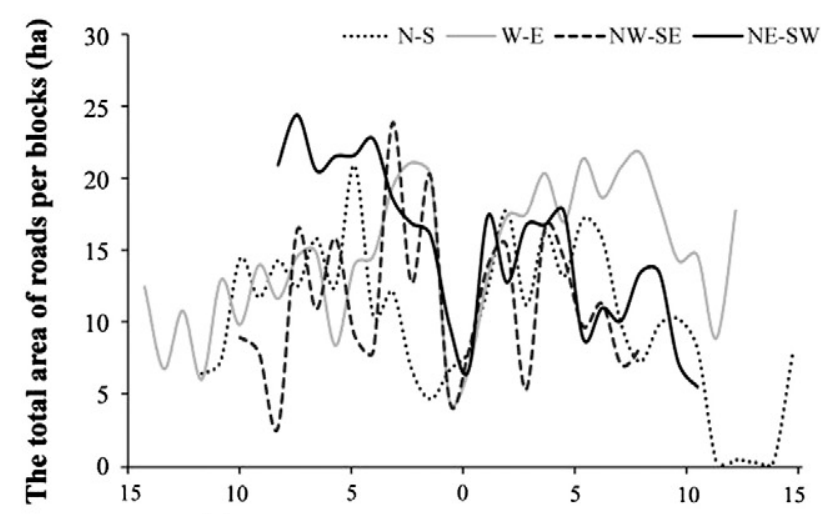

(c) Distance form the city center $(\mathrm{km})$

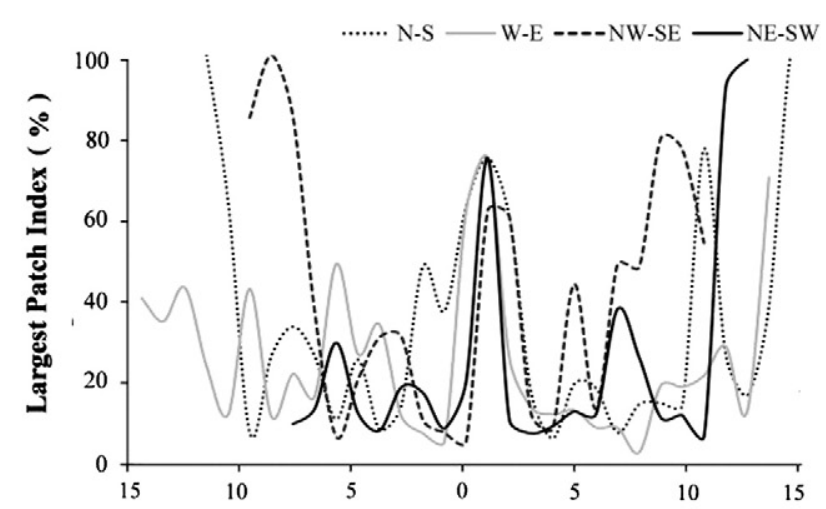

(e) Distance form the city center ( $\mathrm{km})$

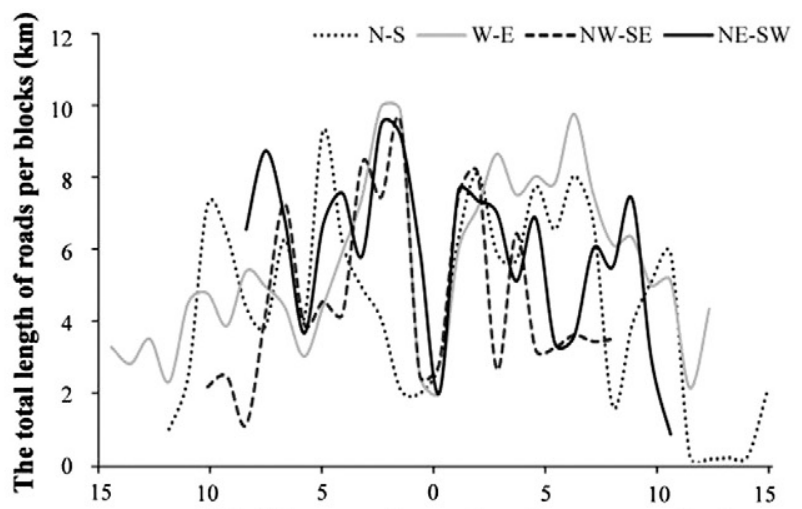

(b) Distance form the city center $(\mathrm{km})$

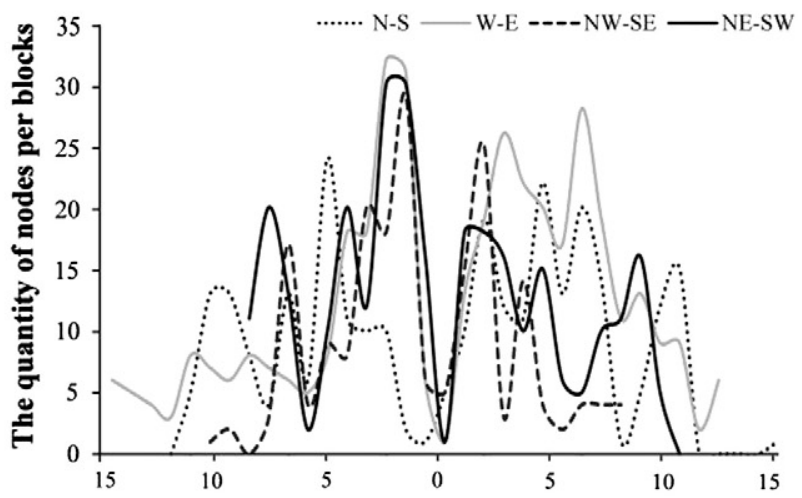

(d) Distance form the city center ( $\mathrm{km})$

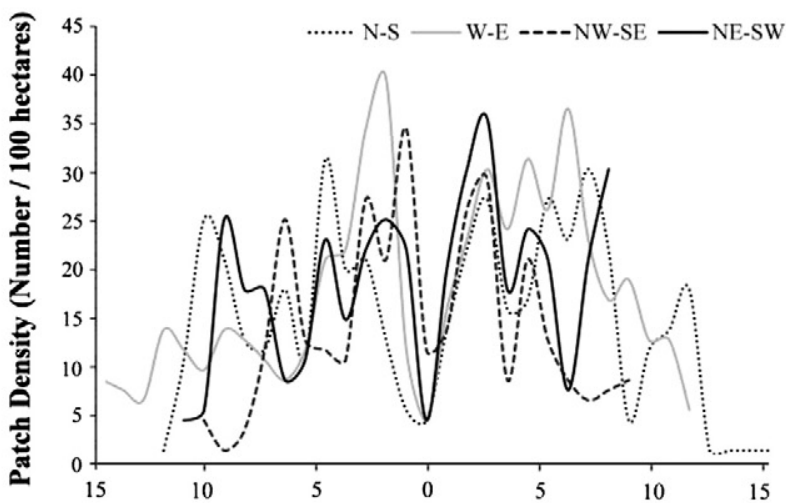

(f) Distance form the city center $(\mathrm{km})$

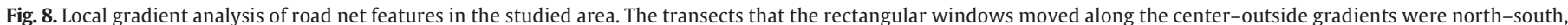

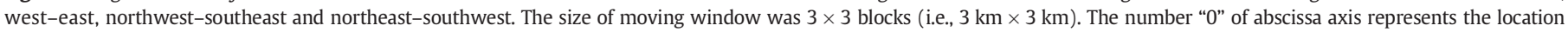
of Tiananmen Square.

a further developmental strategy in pedestrian ancillaries, facing a growing problem in traffic conflicts between vehicles and people.

\subsection{Road stocks and urban thermal environment}

Urban roads are not only places with intensive thermal discharge resulting from human activities, but are also typically impervious surfaces. Compared with natural green spaces, pavement materials, such as cement and asphalt with high rates of heat absorption and conduction, give urban roads different thermodynamic properties. The spatial distribution results of urban road system stocks in this study are similar to the LST (Land Surface Temperature) studies conducted in the central area of Beijing (Ji et al., 2006; Xiao et al., 2007). The preliminary results in our on-going study have already implied a strong correlation among spatial indicators of urban road networks, NDVI (Normalized Difference Vegetation Index) and LST. Linking various spatial attributes of urban road networks to the intensity, quantity and distribution of LST and NDVI may help develop a new approach to quickly grasp important information about the overall UHI (Urban Heat Island) maps and study the relations between urban thermal environments and human activities.

\section{Conclusion}

Through field surveys and investigation into the procedures of urban road engineering construction, a GIS-based MS computation model 


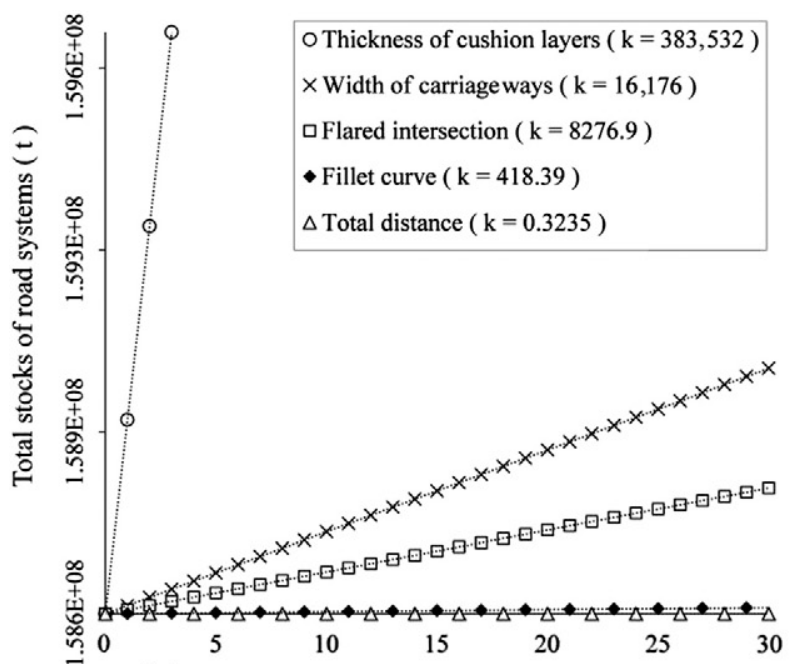

(a) Increment of different factor $(\mathrm{cm})$

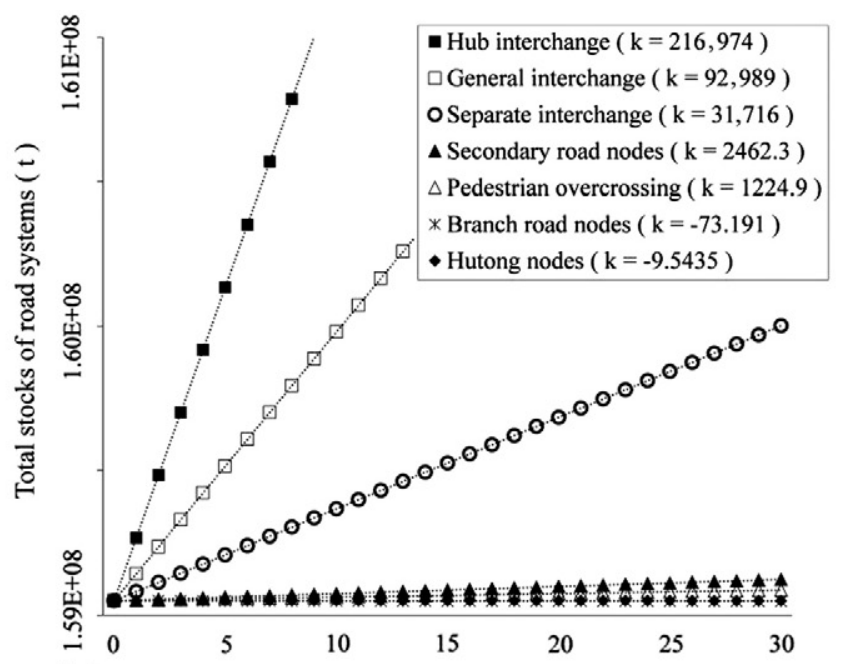

(b) Increment of 3 nodes or ancillary facilities (quantity)

Fig. 9. Sensitivity analysis for stock model of urban road system.

for urban road systems was built. Using Beijing as an example, local parameters were established mainly by survey and high-resolution remote sensing imagery. We further analyzed the types, composition, scale and spatial distribution of MS in urban road systems within the 5th ring. Then, a sensitivity analysis was implemented to interpret the contribution of different variables to the total stocks. Finally, the study produced various constructive results: 1 . The total stocks in the entire road system reached 159 million tons, of which nearly $80 \%$ was stored in road facilities and $20 \%$ in ancillary facilities. 2 . Macadam has the largest stock (111 million tons), while SMA, PUR and APP account for smaller parts of the overall stock system. 3. Pedestrian overcrossings have the highest stocks per unit area, followed by interchanges, with branch roads having the lowest. 4. The cross-sectional structural parameters of branch and neighborhood roads will have a large impact on the scale of MS throughout the whole road system, while total length is the minimal impact indicator. 5. The grade proportion of roads in Beijing is unreasonable; expressways and arterial roads were excessively emphasized, while minor roads, such as secondary roads and branch roads, were relatively ignored.

However, further improvements are still needed. 1) Since the parameters of cross-section structure are static, we have not considered the effects of technological innovation on stocks (e.g. the promulgation and implementation of new standards). 2) The underground ancillary facilities, such as underpass bridges and pedestrian underpasses, were not considered due to a lack of data. In future studies, the inter-annual changes should be investigated, and the dynamic coupling between stocks and fluxes and between road systems and traffic systems should be discussed, so as to develop a further understanding of the correlations among urban infrastructure, human activities and their environmental impacts.

\section{Conflict of interest statement}

We declare that we have no conflict of interest.

\section{Acknowledgements}

This research was supported by National Foundation of Natural Sciences of China $(41171442,70873121)$, the State Key Laboratory of Urban \& Regional Ecology (SKLURE2008-1-01) and the 135 Knowledge Innovation Project of Chinese Academy of Sciences (YSW2013-B04). We thank Xiaogang Wu and Yuanzheng Li for their assistance. We also thank two anonymous reviewers for providing relevant literature and for the helpful discussions and comments.

\section{References}

Baccini P. Understanding regional metabolism for a sustainable development of urban systems. Environ Sci Pollut Res 1996;3:108-11.

Bergsdal H, Brattebo H, Bohne RA, Mueller DB. Dynamic material flow analysis for Norway's dwelling stock. Build Res Inf 2007:35:557-70.

BMCT (Road Administration of Beijing Municipal Commission of Transport). Compilation of statistics; 2011.

Brunner PH. Reshaping urban metabolism. J Ind Ecol 2007;11:11-3.

Chen SQ, Fath BD, Chen B. Information indices from ecological network analysis for urban metabolic system. Procedia Environ Sci 2010;2:720-4.

D'Alisa G, Di Nola MF, Giampietro M. A multi-scale analysis of urban waste metabolism: density of waste disposed in Campania. J Clean Prod 2012;35:59-70.

Daigo I, Matsumoto Y, Matsuno Y, Adachi Y. Material stock and flow analysis of stainless steel based on mass balances of $\mathrm{Cr}$ and Ni. Tetsu To Hagane 2009;95:506-14.

Dall'O' G, Galante A, Torni M. A methodology for the energy performance classification of residential building stock on an urban scale. Energ Build 2012:48:211-9.

Diamond ML, Melymuk L, Csiszar SA, Robson M. Estimation of PCB stocks, emissions, and urban fate: will our policies reduce concentrations and exposure? Environ Sci Technol 2010;44:2777-83.

Duvigncaud P, Denayer-DeSmct S. L'ecosysteme urbain bruxellois. Productivite biologique en Belgique. SCOPE. Travaux de la Section beige du Programme Biologique International Gembloux; 1977.

Forkes J. Nitrogen balance for the urban food metabolism of Toronto, Canada. Resour Conserv Recycl 2007;52:74-94.

Gandy M. Rethinking urban metabolism: water, space and the modern city. City 2004;8: $363-79$.

Gerst MD, Graedel TE. In-use stocks of metals: status and implications. Environ Sci Technol 2008;42:7038-45.

Goudie AS. The human impact on the natural environment: past, present, and future; 2009 [Wiley.com]

Guo SJ, Tan JH, Duan JC, Ma YL, Yang FM, He KB, et al. Characteristics of atmospheric non-methane hydrocarbons during haze episode in Beijing, China. Environ Monit Assess 2012;184:7235-46.

Han J, Xiang WN. Analysis of material stock accumulation in China's infrastructure and its regional disparity. Sustain Sci 2012:1-12.

Hedbrant J. Stockhome: a spreadsheet model of urban heavy metal metabolism. Water Air Soil Pollut 2001:1:55-66.

Hu D, You F, Zhao YH, Yuan Y, Liu TX, Cao AX, et al. Input, stocks and output flows of urban residential building system in Beijing city, China from 1949 to 2008. Resour Conserv Recycl 2010a:54:1177-88.

Hu MM, Pauliuk S, Wang T, Huppes G, van der Voet E, Muller DB. Iron and steel in Chinese residential buildings: a dynamic analysis. Resour Conserv Recycl 2010b;54:591-600.

Huang SL, Lai HY, Lee CL. Energy hierarchy and urban landscape system. Landsc Urban Plan 2001:53:145-61.

ITE (Institute of Transportation Engineers). Planning urban arterial and freeway systems: a proposed, revised recommended practice of the Institute of Transportation Engineers (TPC-RP-015B); 1997.

Ji CP, Liu WD, Xuan CY. Impact of urban growth on the heat island in Beijing. Chinese J Geophys-China 2006;49:69-77.

Kennedy C, Cuddihy J, Engel-Yan J. The changing metabolism of cities. J Ind Ecol 2007;11: 43-59. 
Kennedy C, Pincetl S, Bunje P. The study of urban metabolism and its applications to urban planning and design. Environ Pollut 2011;159:1965-73.

Kleijn R, Huele R, van der Voet E. Dynamic substance flow analysis: the delaying mechanism of stocks, with the case of PVC in Sweden. Ecol Econ 2000;32:241-54.

Kovanda J, Havranek M, Hak T. Calculation of the "Net additions to stock" indicator for the Czech Republic using a direct method. J Ind Ecol 2007;11:140-54.

Li GL, Bai XM, Yu S, Zhang H, Zhu YG. Urban phosphorus metabolism through food consumption. J Ind Ecol 2012;16:588-99.

Lichtensteiger T, Baccini P. Exploration of urban stocks. detail 2008; 5: 16

Liu JR, Wang RS, Yang JX. Metabolism and driving forces of Chinese urban household consumption. Popul Environ 2005;26:325-41.

Matsuno Y, Takahashi KI, Adachi Y, Nakamura J, Elvidge C. Calculation of the in-use stock of materials in urban with nocturnal light image. Urban remote sensing event, 2009 Joint. IEEE; 20091-5.

MCC (Ministry of Construction of China). Code for transport planning on urban road (GB50220-95); 1995.

McMillan CA, Moore MR, Keoleian GA, Bulkley JW. Quantifying US aluminum in-use stocks and their relationship with economic output. Ecol Econ 2010;69:2606-13.

MOHURD (Ministry of Housing Urban-Rural Development of the People's Republic of China). China urban construction statistical yearbook. Beijing: China Planning Press; 2011.

MOHURD Ministry of Housing, Urban-Rural Development of the People's Republic of China. Code for planning of intersections on urban roads (GB 50647-2011). Beijing: Beijing Planning Press; 2011.

Muller DB. Stock dynamics for forecasting material flows - case study for housing in The Netherlands. Ecol Econ 2006;59:142-56.

Newman PWG. Sustainability and cities: extending the metabolism model. Landsc Urban Plan 1999;44:219-26.

Rees WE. Ecological footprints and appropriated carrying capacity: what urban economics leaves out. Environ Urban 1992;4:121-30.

Russam K, Coleman JD. The effect of climatic factors on subgrade moisture conditions. Geotechnique 1961;11:22-8.

Sahely HR, Dudding S, Kennedy CA. Estimating the urban metabolism of Canadian cities: Greater Toronto area case study. Can J Civil Eng 2003;30:468-83.
Satterthwaite D. Cities' contribution to global warming: notes on the allocation of greenhouse gas emissions. Environ Urban 2008;20:539-49.

SBTS (The State Bureau of Technology Supervision). Urban geographical feature - city road, road intersection, block and municipal piping system rules for coding structure (GB/T 14395-93); 1993.

Schiller G. Urban infrastructure: challenges for resource efficiency in the building stock. Build Res Inf 2007;35:399-411.

Sorkin M. Learning from the hutong of Beijing and the lilong of Shanghai. Archit Rec 2008;196.

Tanikawa H, Hashimoto S. Urban stock over time: spatial material stock analysis using 4d-GIS. Build Res Inf 2009;37:483-502.

Tanikawa H, Hashimoto S, Moriguchi Y. Estimation of material stock in urban civil infrastructures and buildings for the prediction of waste generation. The Fifth International Conference on Ecobalance; 2002. p. 803-6.

Tanikawa H, Inadu R, Hashimoto S, Kaneko S. Estimation of historical/spatial changes in subsurface material stock related to the construction sector of urban areas in Japan. From headwaters to the ocean: hydrological changes and watershed management: 2009591-7.

Tarr JA. The metabolism of the industrial city the case of Pittsburgh. J Urban Hist 2002;28: 511-45.

Wang JL, Graedel TE. Aluminum in-use stocks in China: a bottom-up study. J Mater Cycles Waste Manag 2010;12:66-82.

Wee BV. Urban transport and sustainability. Sustainable Urban Environments. Netherlands: Springer; 2012243-61.

Wolman A. The metabolism of cities. Sci Am 1965;213:179-90.

Xiao RB, Ouyang ZY, Zheng H, Li WF, Schienke EW, Wang XK. Spatial pattern of impervious surfaces and their impacts on land surface temperature in Beijing, China. J Environ Sci-China 2007;19:250-6.

Yamaguchi Y, Shimoda Y, Mizuno M. Simulation support in designing the transformation of urban building stock and energy infrastructure. Build Simul 2007:1564-71.

Yin XH, Jia YH, Niu ZH. Research on traffic jam charging policy for vehicles on highway in Chinese megalopolis. Management Science and Engineering (ICMSE), 2012 International Conference on. IEEE; 2012. p. 1911-6. 